\title{
PENGARUH GAYA KEPEMIMPINAN OTORITER DAN MOTIVASI TERHADAP KINERJA KARYAWAN RESTAURANT PAGI SORE CABANG SUNGAI LILIN
}

\author{
Feri Supriyanto \\ ferisupriyanto@stier.ac.id \\ Dosen STIE Rahmaniyah Sekayu
}

\begin{abstract}
Tujuan dilakukannya penelitian ini adalah untuk mengetahui pengaruh gaya kepemimpinan otoriter terhadap kinerja karyawan Restaurant Pagi Sore Cabang Sungai Lilin, pengaruh motivasi terhadap kinerja karyawan Restaurant Pagi Sore Cabang Sungai Lilin, dan pengaruh gaya kepemimpinan otoriter dan motivasi terhadap kinerja karyawan Restaurant Pagi Sore Cabang Sungai Lilin. Jenis penelitian menggunakan pendekatan kuantitatif, sumber data yang digunakan dalam pengumpulan data mencakup data primer dan data sekunder. Variabel dalam penelitian ini adalah gaya kepemimpinan, motivasi, dan kinerja karyawan yang diukur dengan menggunakan Ordinal.

Populasi yang terdapat dalam penelitian ini berjumlah 48 orang, dan jumlah sampel dalam penelitian ini adalah 43 responden. Hasil penelitian ini menemukan bahwa gaya kepemimpinan otoriter berpengaruh signifikan terhadap kinerja karyawan Restaurant Pagi Sore Cabang Sungai Lilin, terdapat pengaruh yang signifikan Motivasi terhadap Kinerja Karyawan Restaurant Pagi Sore Cabang Sungai Lilin, dan secara simultan terdapat pengaruh yang signifikan Gaya Kepemimpinan Otoriter terhadap Kinerja Karyawan Restaurant Pagi Sore Cabang Sungai Lilin.
\end{abstract}

Kata kunci: gaya kepemimpinan otoriter, motivasi, dan kinerja karyawan

\section{PENDAHULUAN}

\subsection{Latar Belakang Masalah}

Kemampuan suatu industri restaurant untuk berkembang sangat bergantung pada kemampuannya memanfaatkan sumber daya yang ada untuk melaksanakan tugas-tugas kerja dalam kerangka kerja yang terarah untuk pengembangan industri. Keberhasilan seluruh pelaksanaan tugas-tugas kerja suatu industri sangat ditentukan oleh tersedianya sumber daya manusia yang berkualitas. Dukungan sumber daya manusia yang berkualitas, tentunya diharapkan dapat berperan aktif sebagai perencana, pelaksana sekaligus sebagai pengawas terhadap semua kegiatan manajemen industri restoran.

Berdasarkan observasi awal yang dilakukan penulis pada Restaurant Pagi Sore Cabang Sungai Lilin, diketahui bahwa terdapat permasalahan masih rendahnya tingkat kinerja karyawan Restaurant Pagi Sore Cabang Sungai Lilin, dapat dilihat dari rendahnya tingkat pelayanan yang diberikan kepada para pengunjung restaurant, karyawan kurang cekatan dalam menjalankan tugasnya sehingga banyaknya pesanan makanan pengujung restaurant yang terlambat dihidangkan dan terkadang pesanan yang di pesan pengunjung lupa mereka 
hidangkan sehingga pengunjung sering komplain, keadaan seperti ini dapat mengakibatkan rendahnya tingkat kepuasan pengunjung. Selanjutnya tingkat kehadiran karyawan masih rendah, hal ini dilihat dari daftar absensi yang masih tinggi angka ketidak hadir karyawan, rendahnya tingkat absensi karyawan tentu akan berdapak buruk pula terhadap kinerja karyawan itu sendiri.

Selain itu, permasalah lain yang terjadi yaitu gaya kepemimpinan yang terkesan acuh serta gaya kepemimpinan yang diterapkan terkesan otoriter dimana komunikasi berlangsung satu arah dari atasan ke bawahan, wewenang mutlak terpusat pada pimpinan, kemudian tidak adanya penghargaan dan pengakuan bagi karyawan berprestasi. Dengan gaya kepemimpinan yang seperti ini tidak akan memberikan dampak yang baik untuk perkembangan karyawan dalam bekerja dan menyebabkan semakin buruknya hasil kinerja karyawan.

Berdasarkan latar belakang masalah tersebut, maka peneliti tertarik untuk melakukan penelitian dengan judul "Pengaruh Gaya Kepemimpinan Otoriter dan Motivasi terhadap Kinerja Karyawan Restaurant Pagi Sore Cabang Sungai Lilin.

\subsection{Perumusan Masalah}

Berdasarkan latar belakang masalah, maka rumusan masalah dalam penelitian ini adalah sebagai berikut:

1. Adakah pengaruh gaya kepemimpinan otoriter terhadap kinerja karyawan Restaurant Pagi Sore Cabang Sungai Lilin?".

2. Adakah pengaruh motivasi terhadap kinerja karyawan Restaurant Pagi Sore Cabang Sungai Lilin?”.

3. Adakah pengaruh gaya kepemimpinan otoriter dan motivasi terhadap kinerja karyawan Restaurant Pagi Sore Cabang Sungai Lilin?”.

\subsection{Tujuan Penelitian}

Tujuan dalam penelitian ini adalah untuk mengetahui:

1. Pengaruh gaya kepemimpinan otoriter terhadap kinerja karyawan Restaurant Pagi Sore Cabang Sungai Lilin.

2. Pengaruh motivasi terhadap kinerja karyawan Restaurant Pagi Sore Cabang Sungai Lilin.

3. Pengaruh gaya kepemimpinan otoriter dan motivasi terhadap kinerja karyawan Restaurant Pagi Sore Cabang Sungai Lilin.

\section{II.LANDASAN TEORI}

\subsection{Gaya Kepemimpinan Otoriter}

Menurut Sutikno (2014:187) gaya kepemimpinan otoriter adalah gaya pemimpin yang memusatkan segala keputusan dan kebijakan yang diambil dari dirinya sendiri secara penuh.

\subsection{Indikator Gaya Kepemimpinan Otoriter}

Menurut Sutikno (2014:187) adapun indikator gaya kepemimpinan otoriter ada 5 (lima) yaitu:

1. Keputusan terpusat

2. Tugas diperinci

3. Subjektifitas Pemimpin

4. Pendapat Hanya Sebagai Lips Service

5. Pengawasan yang Ketat 


\subsection{Pengertian Motivasi}

Menurut George dan Jones (2015:175), motivasi kerja adalah suatu dorongan secara psikologis kepada seseorang yang menentukan arah dari perilaku (direction of behavior) seseorang dalam suatu organisasi, tingkat usaha (level of effort), dan tingkat kegigihan atau ketahanan dalam menghadapi suatu halangan atau masalah (level of persistence).

\subsection{Indikator Motivasi}

Indikator motivasi kerja menurut George dan Jones (2015:186), adalah sebagai berikut:
1. Perilaku Karyawan
2. Usaha Karyawan
3. Kegigihan Karyawan

\subsection{Pengertian Kinerja}

Mathis dan Jackson (2013:269) menyatakan bahwa kinerja pada dasarnya adalah apa yang dilakukan atau tidak dilakukan oleh karyawan dalam mengemban pekerjaannya.

\subsection{Indikator Kinerja}

Indikator untuk mengukur sejauh mana karyawan mencapai kinerja menurut Mathis dan Jackson (2013:79) adalah sebagai berikut:
1. Kuantitas output
2. Kualitas output
3. Ketepatan waktu
4. Komunikasi

\subsection{Kerangka Pemikiran}

Berdasarkan latar belakang di atas dan tinjauan pustaka yang telah dipaparkan sebelumnya, maka sebagai kerangka pemikiran digambarkan secara sederhana sebagai berikut:

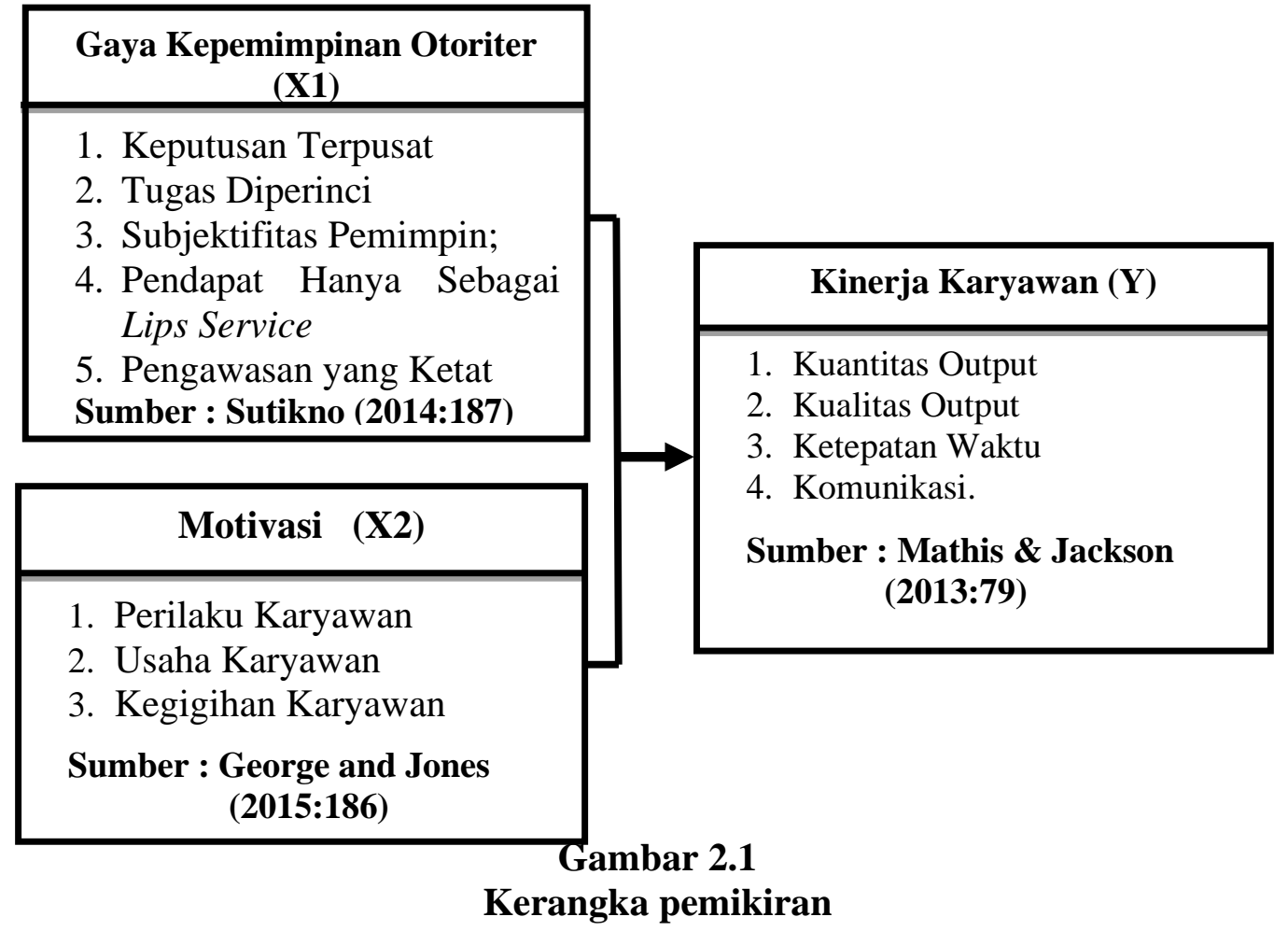




\section{METODOLOGI PENELITIAN}

\subsection{Lokasi dan Waktu Penelitian}

Dalam rangka pengumpulan data yang diperlukan penulis melakukan pemilihan objek untuk penelitian ini pada Restaurant Pagi Sore Cabang Sungai Lilin. Adapun waktu pelaksanaan penelitian ini yaitu \pm 3 bulan.

\subsection{Desain Penelitian}

Penelitian ini bersifat deskriptif dan verifikatif. Penelitian yang sifatnya deskriptif, bertujuan untuk mendeskripsikan karakteristik variabel yang diteliti secara empirik.

\subsection{Jenis dan Sumber Data}

Dalam penelitian ini sumber data yang digunakan dalam pengumpulan data mencakup data primer dan data sekunder.

\subsection{Teknik Pengumpulan Data}

Sugiyono (2014:135), untuk mendapatkan data dan informasi yang dapat mendukung tercapainya tujuan penulis, maka dalam penulisan ini digunakan tiga tahap kegiatan yang dilakukan. Adapun tahap-tahap penelitian ini, yaitu sebagai berikut:
1. Wawancara (interview)
2. Kuesioner (angket)
3. Dokumentasi

\subsection{Definisi Operasionalisasi Variabel Penelitian}

Menurut Sugiyono (2014:139) variabel penelitian adalah suatu atribut atau sifat dari orang, objek atau kegiatan yang memiliki variasi tertentu yang diterapkan oleh peneliti untuk dipelajari dan ditarik kesimpulannya. Dalam penelitian ini terdapat tiga variabel yang digunakan yaitu sebagai berikut:

1. Variabel Independen (variabel bebas), yaitu suatu variabel yang mempengaruhi variabel lainnya. Dalam penelitian ini variabel independen adalah gaya kepemimpinan otoriter (X1) dan motivasi (X2).

2. Variabel dependen (tidak bebas/terikat), yaitu suatu variabel yang dipengaruhi oleh variabel lainya. Dalam penelitian ini variabel dependen adalah kinerja karyawan.

\section{Tabel 3.1}

\section{Definisi Operasional}

\begin{tabular}{|c|c|c|c|c|}
\hline No & Variabel & Definisi Variabel & Indikator & Skala \\
\hline 1 & \begin{tabular}{|l} 
Gaya \\
Kepemimpinan \\
Otoriter \\
(X1)
\end{tabular} & $\begin{array}{lr}\text { Gaya kepemimpinan } \\
\text { Otoriter adalah } & \text { gaya } \\
\text { pemimpin } & \text { yang } \\
\text { memusatkan } & \text { segala } \\
\text { keputusan } & \text { dan } \\
\text { kebijakan yang } & \text { diambil } \\
\text { dari dirinya } & \text { sendiri } \\
\text { secara } & \text { penuh. } \\
\text { (Sutikno, 2014:187) }\end{array}$ & $\begin{array}{ll}\text { 1. } & \text { Keputusan } \\
\text { Terpusat } \\
\text { 2. }\end{array}$ & Ordinal \\
\hline
\end{tabular}




\begin{tabular}{|c|c|c|c|c|}
\hline 2 & $\begin{array}{l}\text { Motivasi } \\
\text { (X2) }\end{array}$ & $\begin{array}{lr}\text { Motivasi kerja } & \text { adalah } \\
\text { suatu dorongan } & \text { secara } \\
\text { psikologis } & \text { kepada } \\
\text { seseorang } & \text { yang } \\
\text { menentukan arah dari } \\
\text { perilaku } & \text { seseorang } \\
\text { dalam suatu organisasi } \\
\text { (George dan Jones, } \\
\text { 2015:175). }\end{array}$ & $\begin{array}{ll}\text { 1. Perilaku } \\
\text { Karyawan } \\
\text { 2. Usaha } \\
\text { Karyawan } \\
\text { 3. Kegigihan } \\
\text { Karyawan }\end{array}$ & Ordinal \\
\hline 3 & $\begin{array}{c}\text { Kinerja } \\
\text { Karyawan } \\
\text { (Y) }\end{array}$ & \begin{tabular}{lr} 
Kinerja & \multicolumn{2}{c}{ pada dasarnya } \\
adalah apa & yang \\
dilakukan atau & tidak \\
dilakukan & oleh \\
karyawan & dalam \\
mengemban & \\
pekerjaannya & (Mathis \\
dan Jackson (2013:269)
\end{tabular} & $\begin{array}{ll}\text { 1. Kuantitas } \\
\text { Output } \\
\text { 2. Kualitas } \\
\text { Output } \\
\text { 3. Ketepatan } \\
\text { Waktu } \\
\text { 4. Komunikasi. }\end{array}$ & Ordinal \\
\hline
\end{tabular}

\subsection{Populasi, Sampel, dan Teknik Pengambilan Sampel}

Menurut Sugiyono (2014: 140) populasi adalah wilayah generalisasi yang terdiri atas objek atau subjek yang mempunyai kualitas dan karakteristik tertentu yang diterapkan oleh peneliti untuk dipelajari dan kemudian ditarik kesimpulannya. Populasi pada penelitian ini adalah karyawan Restaurant Pagi Sore Cabang Sungai Lilin Kabupaten Musi Banyuasin yang berjumlah 48 orang karyawan.

Menurut Sugiyono (2014: 139), Sampel adalah bagian dari jumlah dan karakteristik yang dimiliki oleh populasi. Dalam menentukan besarnya jumlah sampel dalam penelitian ini ditentukan dengan rumus slovin dengan jumlah sampel adalah 43 responden. Adapun teknik sampling yang digunakan dalam penelitian ini adalah menggunakan metode non-probability sampling (pengambilan sampel secara acak).

\subsection{Teknik Analisis Data}

Analisis data yang digunakan dalam penelitian ini adalah. menggunakan program SPSS ( Statistical Product and Service Solution ) For Windows versi 22.0. Adapun teknik analisis data yang digunakan dalam penelitian ini, yaitu:
a. Uji Validitas
b. Uji Reliabilitas
c. Uji Asumsi Klasik
d. Uji Normalitas
e. Uji Multikolinieritas
f. Uji Heteroskedastisitas
g. Analisis Regresi Linier Berganda
h. Analisis Korelasi
i. Uji Hipotesis

\section{HASIL PENELITIAN DAN PEMBAHASAN}

Berikut ini disajikan pengujian Pengaruh Gaya Kepemimpinan Otoriter dan Motivasi terhadap Kinerja Karyawan Restaurant Pagi Sore Cabang Sungai Lilin. 


\subsection{Hasil Penelitian}

\subsubsection{Uji Validitas}

Hasil uji validitas dengan mengunakan bantuan program SPSS for windows 22.0 dapat disajikan dalam tabel berikut ini :

Tabel 4.1

Hasil Pengujian Validitas Variabel Gaya Kepemimpinan Otoriter (X1)

\begin{tabular}{|c|c|c|c|c|}
\hline No & Indikator & $\begin{array}{c}\text { Koefisien Korelasi } \\
\text { (r-hitung) }\end{array}$ & $\begin{array}{c}\text { Nilai Kritis } \\
\text { (r-tabel) }\end{array}$ & Keterangan \\
\hline 1 & $\mathrm{X} 1.1$ & 0,743 & 0,301 & Valid \\
\hline 2 & $\mathrm{X} 1.2$ & 0,793 & 0,301 & Valid \\
\hline 3 & $\mathrm{X} 1.3$ & 0,524 & 0,301 & Valid \\
\hline 4 & $\mathrm{X} 1.4$ & 0,633 & 0,301 & Valid \\
\hline 5 & $\mathrm{X} 1.5$ & 0,806 & 0,301 & Valid \\
\hline 6 & $\mathrm{X} 1.6$ & 0,479 & 0,301 & Valid \\
\hline 7 & $\mathrm{X} 1.7$ & 0,734 & 0,301 & Valid \\
\hline 8 & $\mathrm{X} 1.8$ & 0,448 & 0,301 & Valid \\
\hline 9 & $\mathrm{X} 1.9$ & 0,633 & 0,301 & Valid \\
\hline 10 & $\mathrm{X} 1.10$ & 0,800 & 0,301 & Valid \\
\hline
\end{tabular}

Sumber : Data kuesioner yang telah diolah, 2021

Berdasarkan hasil uji validitas pada Tabel 4.1 menunjukan bahwa $r$ hitung $>\mathrm{r}$ tabel sebesar 0,301, dan dapat disimpulkan bahwa semua item pertanyaan pada variabel gaya kepemimpinan otoriter dinyatakan valid.

Tabel 4.2

Hasil Pengujian Validitas Variabel Motivasi (X2)

\begin{tabular}{|c|c|c|c|c|}
\hline No & Indikator & $\begin{array}{c}\text { Koefisien Korelasi } \\
\text { (r-hitung) }\end{array}$ & $\begin{array}{c}\text { Nilai Kritis } \\
\text { (r-tabel) }\end{array}$ & Keterangan \\
\hline 1 & X2.1 & 0,758 & 0,301 & Valid \\
\hline 2 & X2.2 & 0,769 & 0,301 & Valid \\
\hline 3 & X2.3 & 0,514 & 0,301 & Valid \\
\hline 4 & X2.4 & 0,668 & 0,301 & Valid \\
\hline 5 & X2.5 & 0,341 & 0,301 & Valid \\
\hline 6 & X2.6 & 0,527 & 0,301 & Valid \\
\hline 7 & X2.7 & 0,585 & 0,301 & Valid \\
\hline 8 & $\mathrm{X} 2.8$ & 0,712 & 0,301 & Valid \\
\hline 9 & $\mathrm{X} 2.9$ & 0,758 & 0,301 & Valid \\
\hline 10 & $\mathrm{X} 2.10$ & 0,769 & 0,301 & Valid \\
\hline
\end{tabular}

Sumber : Data kuesioner yang telah diolah, 2021

Berdasarkan hasil uji validitas pada Tabel 4.2 menunjukan bahwa $r$ hitung $>\mathrm{r}$ tabel. Sehingga dapat disimpulkan bahwa semua item pertanyaan pada variabel motivasi dinyatakan valid. 
Tabel 4.3

Hasil Pengujian Validitas Variabel Kinerja Karyawan (Y)

\begin{tabular}{|c|c|c|c|c|}
\hline No & Indikator & $\begin{array}{c}\text { Koefisien Korelasi } \\
\text { (r-hitung) }\end{array}$ & $\begin{array}{c}\text { Nilai Kritis } \\
\text { (r-tabel) }\end{array}$ & Keterangan \\
\hline 1 & Y1 & 0,591 & 0,301 & Valid \\
\hline 2 & Y2 & 0,700 & 0,301 & Valid \\
\hline 3 & Y3 & 0,758 & 0,301 & Valid \\
\hline 4 & Y4 & 0,710 & 0,301 & Valid \\
\hline 5 & Y5 & 0,584 & 0,301 & Valid \\
\hline 6 & Y6 & 0,758 & 0,301 & Valid \\
\hline 7 & Y7 & 0,713 & 0,301 & Valid \\
\hline 8 & Y8 & 0,676 & 0,301 & Valid \\
\hline 9 & Y9 & 0,740 & 0,301 & Valid \\
\hline 10 & Y10 & 0,744 & 0,301 & Valid \\
\hline
\end{tabular}

Sumber : Data kuesioner yang telah diolah, 2021

Berdasarkan hasil uji validitas pada Tabel 4.3 menunjukan bahwa $r$ hitung $>\mathrm{r}$ tabel. Sehingga dapat disimpulkan bahwa semua item pertanyaan pada variabel kinerja karyawan dinyatakan valid.

\subsubsection{Uji Reliabilitas}

Adapun hasil uji reliabiitas yang dilakukan terhadap instrumen penelitian ini dapat dijelaskan pada tabel berikut ini :

Tabel 4.4

Hasil Uji Reliabilitas Butir Kuesioner

\begin{tabular}{|c|l|c|c|}
\hline No. & \multicolumn{1}{|c|}{ Butir Dalam Kuesioner } & Nilai Alpha & Status \\
\hline 1 & Gaya Kepemimpinan Otoriter (X1) & 0,852 & Reliabel \\
\hline 2 & Motivasi (X2) & 0,832 & Reliabel \\
\hline 3 & Kinerja Karyawan (Y) & 0,873 & Reliabel \\
\hline
\end{tabular}

Sumber: Data kuesioner yang telah diolah, 2021

Berdasarkan hasil pengolahan data dengan bantuan SPSS for windows, versi 22.0 diperoleh hasil uji reliabilitas variabel Gaya Kepemimpinan Otoriter (X1) di menunjukan nilai Alpha sebesar 0,852, variabel Motivasi (X2) menunjukan nilai Alpha sebesar 0,832, dan variabel Kinerja Karyawan (Y) menunjukan nilai Alpha sebesar 0,873. Dengan demikian semua variabel-variabel yang digunakan dalam penelitian ini dinyatakan reliabel.

4.1.3. Uji Asumsi Klasik

4.1.3.1. Uji Normalitas

Pengujian normalitas data dilakukan dengan menggunakan tes Kolmogrof Smimov (Tes K-S), dengan menetapkan taraf signifikan $5 \%$ atau $a=0,05$. Menurut Sudjana (2016: 138) data dapat dikatakan berdistribusi normal jika taraf signifikan (Asymp. Sig) $\geq 0,05$. Sebaliknya jika taraf signifikan (Asymp. Sig) $<0$, 05 maka data dikatakan tidak berdistribusi normal. Berikut ini hasil uji normalitas dengan program SPSS versi 22.0: 
Tabel 4.5

Hasil Uji Normalitas

One-Sample Kolmogorov-Smirnov Test

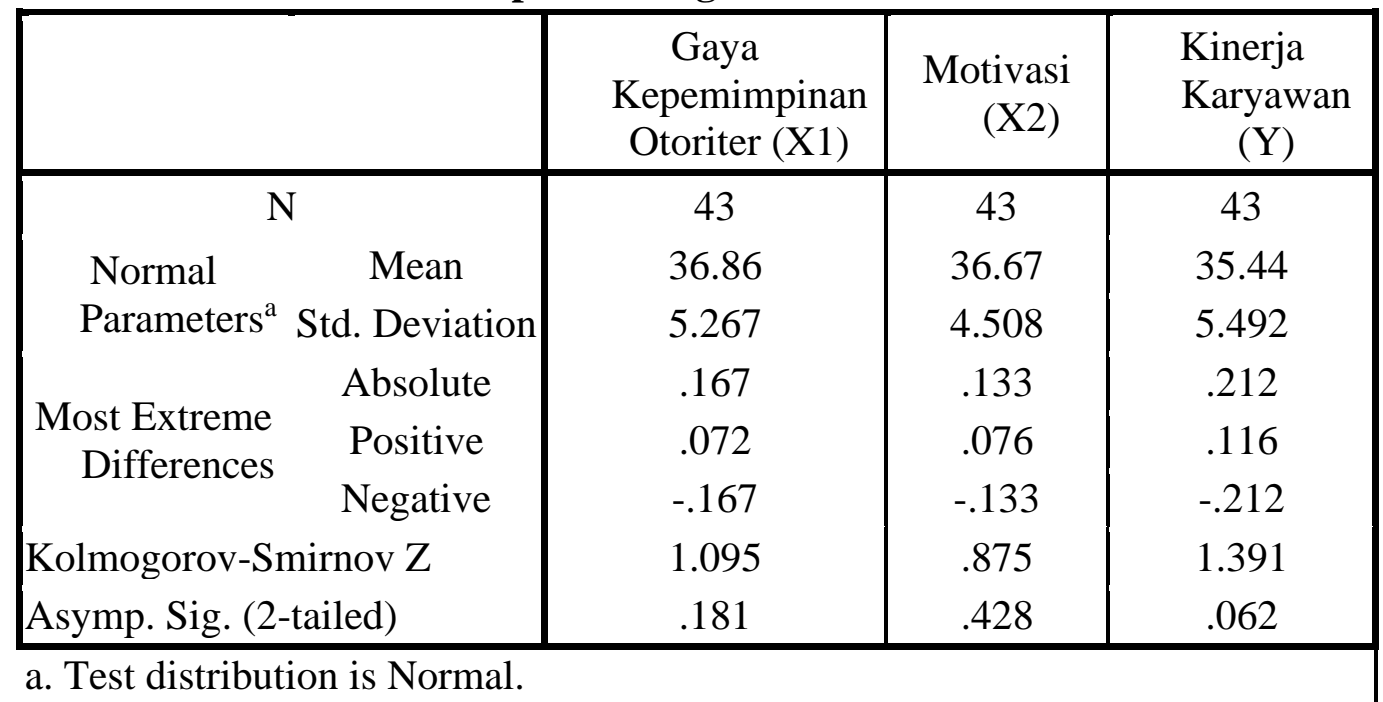

Sumber : Data kuesioner yang telah diolah, 2021

Hasil perhitungan normalitas variabel gaya kepemimpinan otoriter (X1) memiliki nilai signifikan $0,181>0,05$ dengan demikian data berdistribusi normal, dan variabel motivasi (X2) memiliki nilai signifikan 0,428>0,05 dengan demikian data berdistribusi normal, dan variabel kinerja karyawan (Y) memiliki nilai signifikan $0,062>0,05$ dengan demikian data berdistribusi normal.

\subsubsection{Uji Multikolinieritas}

Tabel 4.6

\section{Hasil Uji Multikolinieritas}

Coefficients $^{\mathbf{a}}$

\begin{tabular}{|c|c|c|c|c|c|c|c|}
\hline \multirow[b]{2}{*}{ Model } & \multicolumn{2}{|c|}{$\begin{array}{r}\text { Unstandardized } \\
\text { Coefficients }\end{array}$} & \multirow{2}{*}{$\begin{array}{c}\begin{array}{c}\text { Standardized } \\
\text { Coefficients }\end{array} \\
\text { Beta }\end{array}$} & \multirow[b]{2}{*}{$\mathrm{t}$} & \multirow[b]{2}{*}{ Sig. } & \multicolumn{2}{|c|}{$\begin{array}{r}\text { Collinearity } \\
\text { Statistics }\end{array}$} \\
\hline & B & Std. Error & & & & Tolerance & VIF \\
\hline 1 (Constant) & 2.528 & 4.476 & & .565 & .575 & & \\
\hline $\begin{array}{l}\text { Gaya Kepemimpinan } \\
\text { Otoriter (X1) }\end{array}$ & .589 & .172 & .565 & 3.429 & .001 & .361 & 2.769 \\
\hline Motivasi (X2) & .306 & .201 & .251 & 1.524 & .135 & .361 & 2.769 \\
\hline
\end{tabular}

A. Dependent Variable: Kinerja Karyawan Y

Sumber : Data kuesioner yang telah diolah, 2021

Dalam Uji multikolinieritas, kriteria pengambilan keputusan penggunaan nilai toleran dan VIF tersebut menurut Ghozali (2014: 104) adalah jika nilai tolerance $>0,10$ atau nilai VIF $<10$ maka tidak ada multikoleniaritas di antara variabel independen. Sebaliknya, jika nilai tolerance $\leq 0,10$ atau nilai VIF $\geq 10$ maka ada multikoleniaritas di antara variabel independen. Berdasarkan Tabel 4.6 diketahui nilai tolerance untuk variabel gaya kepemimpinan otoriter (X1) dan motivasi $(X 2)$ adalah $0,361>0,10$. Sementara nilai VIF untuk variabel gaya kepemimpinan otoriter (X1) dan motivasi (X2) adalah 2,769 < 10,00. Maka dapat disimpulkan bahwa tidak terjadi gejala multikolineritas dalam model regresi. 


\subsubsection{Uji Heteroskedastisitas}

Pengujian heteroskedastisitas dalam penelitian ini dilakukan dengan melihat grafik plot antara prediksi nilai variabel terikat dengan residualnya. Kriteria pengambilan keputusan dalam pengujian ini menurut Ghozali (2014: 134) adalah jika ada pola tertentu, seperti titik-titik yang ada membentuk pola tertentu yang teratur (bergelombang, melebar kemudian menyempit) maka telah terjadi heteroskesdatisitas, dan sebaliknya.

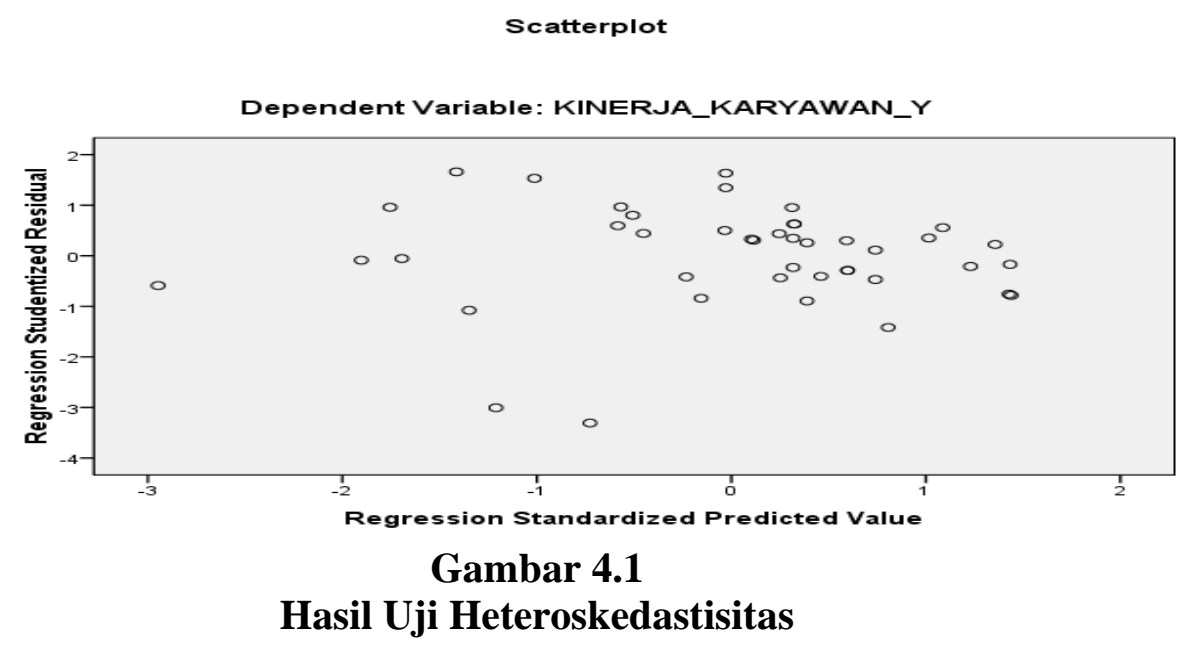

Sumber : Data kuesioner yang telah diolah, 2021

Dari Gambar 4.1 menunjukkan titik-titik data penyebaran diatas dan dibawah aatau disekitar angka 0, titik-titik tidak mengumpul hanya diatas atau dibawah saja, penyebaran titik-titik data tidak membentuk pola bergelombang melebar kemudian menyempit dan melebar kembali. Dengan demikian dapat disimpulkan bahwa tidak terjasi masalah heteroskedastistas.

\subsubsection{Uji Regresi Linear Berganda}

Hasil analisis regresi linear berganda melalui program SPSS Versi 22.0 didapat hasil sebagai berikut:

Tabel 4.7

Hasil Uji Regresi Linear Berganda

Coefficients ${ }^{\mathbf{a}}$

\begin{tabular}{|c|c|c|c|c|c|}
\hline \multirow[b]{2}{*}{ Model } & \multicolumn{2}{|c|}{$\begin{array}{r}\text { Unstandardized } \\
\text { Coefficients }\end{array}$} & \multirow{2}{*}{$\begin{array}{c}\text { Standardized } \\
\text { Coefficients } \\
\text { Beta }\end{array}$} & \multirow[b]{2}{*}{$\mathrm{t}$} & \multirow[b]{2}{*}{ Sig. } \\
\hline & B & Std. Error & & & \\
\hline $1 \quad$ (Constant) & 2.528 & 4.476 & & .565 & .575 \\
\hline $\begin{array}{l}\text { Gaya Kepemimpinan } \\
\text { Otoriter (X1) }\end{array}$ & .589 & .172 & .565 & 3.429 & .001 \\
\hline Motivasi (X2) & .306 & .201 & .251 & 1.524 & .135 \\
\hline
\end{tabular}

Sumber : Data kuesioner yang telah diolah, 2021 
Berdasarkan Tabel 4.7, tersebut diatas diperoleh nilai Constant (a) sebesar 2.528, nilai koefisien X1 : 0,589 dan Koefisien X2 : 0,306 sehingga diperoleh persamaan regresi linear berganda $\mathrm{Y}=2.528+0,589 \mathrm{X} 1+0,306 \mathrm{X} 2$. Dari persamaan regresi di atas maka dapat diinterpretasikan beberapa hal, antara lain:

1. Nilai konstanta sebesar 2.528 yang berarti bahwa jika nilai variabel (X1) sebesar 0 dan nilai variabel $(\mathrm{X} 2)$ sebesar 0 , maka variabel $\mathrm{Y}$ akan memiliki nilai sebesar 2.528 .

2. Nilai koefisien regresi untuk variabel $\mathrm{X} 1$ adalah positif sebesar 0,589 dan hal ini menunjukkan bahwa setiap kenaikan 1 satuan variabel X1 maka akan menaikkan nilai variabel $Y$ sebesar 0,589 satuan dengan asumsi variabel lain bernilai tetap.

3. Nilai koefisien regresi untuk variabel X2 adalah negatif sebesar 0,306 dan hal ini menunjukkan bahwa setiap menurun 1 satuan variabel X2 maka akan menurunkan nilai variabel $\mathrm{Y}$ sebesar 0,306 satuan dengan asumsi variabel lain bernilai tetap.

\subsubsection{Analisis Korelasi}

Analisis korelasi digunakan untuk mengetahui keeratan hubungan antara dua variabel yaitu variabel bebas yaitu gaya kepemimpinan otoriter (X1), motivasi (X2) dan variabel terikat yaitu kinerja karyawan (Y), serta untuk mengetahui arah hubungan yang terjadi antar variabel.

Tabel 4.8

Hasil Analisis Koefisien Korelasi

Model Summary ${ }^{b}$

\begin{tabular}{|c|c|c|c|c|}
\hline Model & $\mathrm{R}$ & $\mathrm{R}$ Square & Adjusted R Square & Std. Error of the Estimate \\
\hline 1 & $.765^{\mathrm{a}}$ & .685 & .576 & 3.578 \\
\hline
\end{tabular}

A. Predictors: (Constant), Gaya Kepemimpinan Otoriter (X1)

B. Dependent Variable: Kinerja Karyawan (Y)

Sumber : Data kuesioner yang telah diolah, 2021

Interprestasi koefisien korelasi mengenai pengaruh gaya kepemimpinan otoriter dan motivasi terhadap kinerja karyawan Restaurant Pagi Sore Cabang Sungai Lilin, diketahui nilai korelasi (R) sebesar 0,765, hal ini menunjukkan hubungan yang kuat antara variabel X1, X2 dan variabel $\mathrm{Y}$ karena berada di kisaran 0,60-0,799.

\subsubsection{Uji Hipotesis}

\subsubsection{Uji t (Uji Parsial)}

Menurut Ghozali (2014: 176), uji t digunakan untuk mengetahui signifikansi antara variabel $\mathrm{X}$ dan variabel $\mathrm{Y}$. Adapun sampel yng digunakan dalam penelitian ini sebanyak 43 responden, sehingga pengujian mengunakan uji t dengan $\mathrm{df}=\mathrm{n}-2$ atau 43-2 $=41$ dan tingkat signifikansi $(\alpha)=5 \%$. Maka diperoleh $\mathrm{t}$ tabel sebesar 2,020. Adapun hasil uji hipotesis (uji t) masing-masing variabel, dapat dilihat pada tabel berikut ini : 
Tabel 4.9

Hasil Uji t Variabel Gaya Kepemimpinan Otoriter (X1) Coefficients $^{\mathbf{a}}$

\begin{tabular}{|c|c|c|c|c|c|}
\hline \multirow{2}{*}{ Model } & \multicolumn{2}{|c|}{$\begin{array}{c}\text { Unstandardized } \\
\text { Coefficients }\end{array}$} & $\begin{array}{c}\text { Standardized } \\
\text { Coefficients }\end{array}$ & \multirow{2}{*}{$\mathrm{T}$} & \multirow{2}{*}{ Sig. } \\
\cline { 2 - 4 } & $\mathrm{B}$ & Std. Error & Beta & \\
\hline $\begin{array}{c}\text { (Constant) } \\
1 \quad \begin{array}{l}\text { Gaya Kepemimpinan } \\
\text { Otoriter (X1) }\end{array}\end{array}$ & 6.032 & 3.902 & & 1.546 & .130 \\
\hline
\end{tabular}

a. Dependent Variable: Kinerja Karyawan (Y)

Sumber : Data kuesioner yang telah diolah, 2021

Tabel 4.10

Hasil Uji t Variabel Motivasi (X2)

Coefficients $^{\mathbf{a}}$

\begin{tabular}{|c|c|c|c|c|c|}
\hline \multirow[b]{2}{*}{ Model } & \multicolumn{2}{|c|}{$\begin{array}{r}\text { Unstandardized } \\
\text { Coefficients } \\
\end{array}$} & \multirow{2}{*}{$\begin{array}{c}\text { Standardized } \\
\text { Coefficients }\end{array}$} & \multirow[b]{2}{*}{$\mathrm{T}$} & \multirow[b]{2}{*}{ Sig. } \\
\hline & B & Std. Error & & & \\
\hline (Constant) & 4.064 & 5.004 & & .812 & .421 \\
\hline Motivasi (X2) & .856 & .135 & .702 & 6.317 & .000 \\
\hline
\end{tabular}

Sumber: Data kuesioner yang telah diolah, 2021

Berdasarkan Tabel 4.9 yang diperoleh dari hasil pengolahan komputerisasi mengunakan program SPSS 22.0, maka dapat diperoleh nilai thitung $(7,612)>$ ttabel (2,020), sehingga dapat ditarik kesimpulan Ho ditolak atau Ha diterima artinya ada Pengaruh Gaya Kepemimpinan Otoriter (X1) dan Motivasi (X2) terhadap Kinerja Karyawan (Y) Restaurant Pagi Sore Cabang Sungai Lilin.

Berdasarkan tabel 4.10 diperoleh nilai thitung $(6,317)>$ ttabel $(2,020)$, sehingga dapat ditarik kesimpulan Ho ditolak atau Ha diterima artinya ada Pengaruh Gaya Kepemimpinan Otoriter (X1) dan Motivasi (X2) terhadap Kinerja Karyawan (Y) Restaurant Pagi Sore Cabang Sungai Lilin.

\subsubsection{2. $\quad$ Uji F (Uji Serempak)}

Pengujian ini digunakan untuk mengetahui apakah koefisien regresi tersebut mempunyai pengaruh yang signifikan atau tidak secara simultan (bersama-sama) antara variabel independen (X1 dan X2) terhadap variabel dependen (Y). Jika Sig. $>$ a $(0,05)$, maka koefisien regresi tidak signifikan. Jika Sig. $<$ a $(0,05)$, maka koefisien regresi signifikan. Berdasarkan hasil pengujian dengan menggunakan SPSS For Windows Versi 22.0, diperoleh hasil pengujian hipotesis (Uji F), yaitu sebagai berikut : 
Tabel 4.11

Hasil Uji Hipotesis (Uji-F)

ANOVA ${ }^{b}$

\begin{tabular}{|ll|r|r|r|c|c|}
\hline \multicolumn{1}{|l|}{ Model } & Sum of Squares & Df & Mean Square & F & Sig. \\
\hline 1 & Regression & 741.743 & 2 & 741.743 & 57.942 & $.000^{\mathrm{a}}$ \\
& Residual & 524.862 & 40 & 12.802 & & \\
& Total & 1266.605 & 42 & & & \\
\hline
\end{tabular}

A. Predictors: (Constant), Gaya Kepemimpinan Otoriter (X1)

B. Dependent Variable: Kinerja Karyawan (Y)

Sumber : Data kuesioner yang telah diolah, 2021

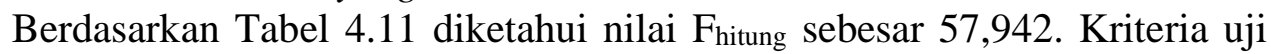
Hipotesis jika : $F_{\text {hitung }}<F_{\text {tabel }}$ maka Ha Ditolak dan jika sebaliknya $F_{\text {hitung }}>F_{\text {tabel }}$ maka Ha diterima. Berdasarkan tabel pada taraf nyata $\mathrm{a}=0,05$ dengan $\mathrm{df}$ pembilang 2 (ditentukan dan banyaknya variabel bebas) dan df penyebut 40 (ditentukan dengan banyak sampel dikurang variabel bebas dikurang satu). Berdasarkan penjelasan diatas diketahui $F_{\text {hitung }}$ 57,942 dan $F_{\text {tabel }}$ 3,23 dimana $F_{\text {hitung }}>F_{\text {tabel }}$ yang berarti Ha diterima atau disimpulkan terdapat Pengaruh Gaya Kepemimpinan Otoriter dan Motivasi terhadap Kinerja Karyawan Restaurant Pagi Sore Cabang Sungai Lilin.

\subsection{Pembahasan Hasil Penelitian}

Penelitian ini telah menunjukkan bahwa gaya kepemimpinan seorang pimpinan dan motivasi mempunyai dampak terhadap kinerja kinerja karyawan Restaurant Pagi Sore Cabang Sungai Lilin. Berdasarkan hasil pengolahan data yang telah dilakukan dalam penelitian ini menunjukkan bahwa variabel Gaya Kepemimpinan Otoriter dan Motivasi mempunyai pengaruh secara signifikan terhadap Kinerja Karyawan Restaurant Pagi Sore Cabang Sungai Lilin.

Dari hasil pengujian parsial (Uji t) ada pengaruh signifikan Gaya Kepemimpinan Otoriter (X1) terhadap Kinerja Karyawan (Y) Restaurant Pagi Sore Cabang Sungai Lilin, terdapat pengaruh signifikan Motivasi (X2) terhadap Kinerja Karyawan (Y) Restaurant Pagi Sore Cabang Sungai Lilin. Berdasarkan uji tersebut masing-masing variabel, Gaya Kepemimpinan Otoriter dan Motivasi berpengaruh signifikan terhadap Kinerja Karyawan Restaurant Pagi Sore Cabang Sungai Lilin.

Berdasarkan hasil dari Uji Hipotesis (Uji F) menunjukkan bahwa Gaya Kepemimpinan Otoriter dan Motivasi secara simultan berpengaruh positif dan signifikan terhadap Kinerja Karyawan. Sehingga dapat disimpulkan bahwa terdapat pengaruh yang signifikan dan simultan antara Gaya Kepemimpinan Otoriter dan Motivasi terhadap Kinerja Karyawan Restaurant Pagi Sore Cabang Sungai Lilin.

Berdasarkan hasil Analisis koefisien korelasi menunjukkan hubungan yang kuat antara variabel X1, X2 dan variabel $\mathrm{Y}$, hal ini berarti seluruh variabel bebas yakni Gaya Kepemimpinan Otoriter dan Motivasi mempunyai kontribusi 
secara bersama-sama terhadap variabel terikat yaitu Kinerja Karyawan Restaurant Pagi Sore Cabang Sungai Lilin.

\section{KESIMPULAN DAN SARAN}

\subsection{Kesimpulan}

Berdasarkan hasil penelitian dan pembahasan yang telah dilakukan, maka dapat disimpulkan bahwa: Terdapat pengaruh yang signifikan Gaya Kepemimpinan Otoriter terhadap Kinerja Karyawan Restaurant Pagi Sore Cabang Sungai Lilin. Terdapat pengaruh yang signifikan Motivasi terhadap Kinerja Karyawan Restaurant Pagi Sore Cabang Sungai Lilin. Secara simultan, terdapat pengaruh yang signifikan Gaya Kepemimpinan Otoriter terhadap Kinerja Karyawan Restaurant Pagi Sore Cabang Sungai Lilin.

\subsection{Saran}

Berdasarkan pada pembahasan dan kesimpulan yang dikemukakan, maka saran yang perlu disampaikan sebagai berikut:

a. Bagi pimpinan Restaurant Pagi Sore Cabang Sungai Lilin untuk membuat kebijakan perusahaan yang bisa mempertahankan indikator-indikator dari kepemimpinan yang ada sekarang dan diharapkan di masa mendatang lebih ditingkatkan lagi dalam upaya meningkatkan kinerja karyawannya agar lebih produktif lagi.

b. Berdasarkan kondisi yang terjadi dilapangan, penelitian ini menghasilkan rekomendasi untuk Restaurant Pagi Sore Cabang Sungai Lilin dengan melakukan perbaikan pekerjaan di masa depan yang berkaitan dengan gaya kepemimpin otoriter, motivasi, dan kinerja karyawan. Dan melakukan perbaikan sesuai dengan standart yang berlaku serta menginovasi agar terciptanya kinerja karyawan yang lebih efektif membantu dalam memenuhi target yang diinginkan perusahaan.

\section{DAFTAR PUSTAKA}

George, J.M., dan Jones, G.R. 2015. Understanding and Managing Organizational Behavior (4thed). New Jersey: Upper Saddle River.

Ghozali, Imam. 2014. Aplikasi Analisis Multivariate Dengan Program SPSS. Edisi 5. Semarang: UNDIP.

Mathis, Robert L. dan Jackson, John H. 2013. Human Resource Management. Edisi Kesepuluh. Jakarta: Salemba Empat.

Sudjana. 2016. Prosedur Penelitian Suatu Pendekatan Praktik. Jakarta: PT. Rineka Cipta

Sugiyono. 2014. Statistika Untuk Penelitian. Bandung: Alfabeta.

Sutikno, Sobri M. 2014. Pemimpin dan Gaya Kepemimpinan. Edisi Pertama. Lombok: Holistica. 